\title{
Morphological and physiological properties of hybrid rice seeds with top-gray chalkiness
}

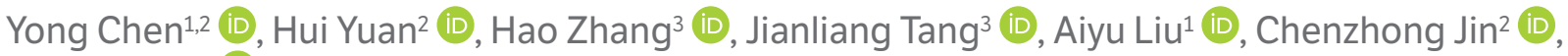 \\ Yihong $\mathrm{Hu}^{2, *}$ (iD \\ 1. Hunan Agricultural University - College of Agronomy - Changsha (Hunan), China. \\ 2. Hunan University of Humanities, Science and Technology - Collaborative Innovation Center for Field Weeds Control of Hunan Province - Loudi \\ (Hunan), China. \\ 3. Hunan Ava Seeds Co., Ltd. - The Quality Inspection Department - Changsha (Hunan), China. \\ Received: May 18, 2020 | Accepted: Oct. 19, 2020 \\ Section Editor: Hector Valenzuela \\ *Corresponding author: huyhongwangyi@163.com \\ How to cite: Chen, Y., Yuan H., Zhang, H., Tang, J., Liu, A., Jin, C. and Hu, Y. (2021). Morphological and physiological properties of hybrid rice \\ seeds with top-gray chalkiness. Bragantia, 80, e0121. https://doi.org/10.1590/1678-4499.20200228
}

\begin{abstract}
Hybrid rice seeds from sterile lines have displayed a new type of heavy chalkiness in the subtropical zone of China in recent years, which was named top-gray chalkiness, resulting in a lower quality of hybrid rice seeds in large-scale production. In this study, the morphological characteristics of the chalky hybrid rice seeds were investigated, the microscopic structures of their chalky parts observed, the $\alpha$-amylase activity and relative nutrient content analyzed, and the germination indexes and microorganism populations of the chalky hybrid seeds determined. The results revealed that top-gray chalkiness in hybrid rice seeds originated from the top site of the grain, and that the chalky part was probably infected by bacteria and fungi to form a gray color and which further resulted in a lower germination rate and germination potential. This observed chalkiness in rice seeds differed from the previously reported rice chalkiness categories both in the occurrence position and color. Besides, the amylopectin content declined in the chalky part and the protein content in the chalky part increased as compared to the normal seeds. This research could provide technical support for the hybrid rice breeding enterprises during the breeding of hybrid rice seeds in large-scale production.
\end{abstract}

Key words: hybrid rice seeds, top-gray chalkiness, germination rate, germination potential.

\section{INTRODUCTION}

Rice (Oriza sativa L.) is the main staple food crop for more than $50 \%$ of the people all over the world. High temperature is a key factor responsible for the formation of chalky grains during the rice ripening period, resulting in a decrease of production and lower quality of products (Nakata et al. 2017). High temperatures induce rice $\alpha$-amylases expression which are strictly regulated by gibberellin acids (GA) to control the chalky grain process, loosen the package of starch granules in the endosperm, and form numerous pits on the surface of these starch granules (Ishimaru et al. 2009).

Over the past decades, many studies have focused on the rice $\alpha$-amylases expressions and the GA receptors in cells. The early research showed that the GA-affinity receptors, which were polypeptides or proteins, were located in the plant plasma membranes (Walker et al. 1994; Lovegrove et al. 1998), whereas latter research indicated that GA signals were perceived in the plant nuclei mediated by a protein with a DELLA domain in plants (Yano et al. 2015; Ueguchi-Tanaka et al. 2007; Hartweck and Olszewski 2006).

For rice grain chalkiness, grains were classified into five types basically according to the appearance of the chalky parts including milky-white chalky rice, white-core chalky rice, white-belly chalky rice, white-based chalky rice, and whiteback chalky rice, where the chalky parts were in the core, near the basal part, or from the belly part of the endosperm (Yoshioka et al. 2007). Although high temperature-induced rice $\alpha$-amylases expression and high humidity available for 
enzyme activity are commonly considered as the main reasons for chalkiness formation, the real intrinsic mechanisms for chalkiness formation are complicated. Chalkiness in rice grains is influenced by a combination of factors including inheritance and environment, and even grain nutrition condition can influence chalkiness formation. For example, the ratio of nitrogen to potassium could regulate the rice chalkiness ratio (Bridgemohan and Bridgemohan 2014). Guo et al. (2011) reported a major quantitative trait locus for the percentage of chalky grains, and Ishimaru et al. (2009) reported a different mechanism for chalkiness formation: The starch accumulated faster around the center of the endosperm than in the lateral part simply due to high-temperature stress, resulting in a loosened starch structure in the white-core chalky rice during the rice ripening period.

China is the largest hybrid rice-producing area in the world. In the 1990s, scientists invented the two-line hybrid rice seed production method depending on photoperiod sensitive and thermosensitive rice materials (Wang and Meng 2005). For this reason, areas of southern parts of China, such as Hainan Province, are often selected as ideal places for hybrid rice breeding fields where the climate characteristics are long sunny days with high temperature. As a result, the glume-open phenomenon is quite common in these rice sterile lines (Fu et al. 2017). For hybrid rice seeds, grain chalkiness is, therefore, more serious than on conventional varieties.

In hybrid rice breeding practices in China in recent years, the authors of this work have observed a new type of grain chalkiness, called top-gray chalky rice. This chalkiness originated from the top site of the endosperm and was gray-colored, unlike the former reported types. It sometimes seriously influences the seed germination rate and can infect healthy seeds during soaking and germination, causing a lower commercial quality of hybrid rice seeds. In some severe cases, it can lead to a whole batch of seeds being discarded, arousing serious field sowing quality complaints from peasants.

Therefore, the objective of this study was to investigate the morphological and physiological properties of top-gray chalky rice seeds to provide technical support for hybrid rice seeds processing during the large-scale production.

\section{MATERIAL AND METHODS}

\section{Investigation of chalkiness ratios of hybrid rice seeds in field}

The investigation of chalkiness of different hybrid rice varieties was conducted from 2017 to 2019 during the summer seasons in the Ava Hainan Breeding Experiment Station which is located in Ledong County, Hainan Province, China $\left(18^{\circ} 29^{\prime} 24^{\prime \prime} \mathrm{N}, 108^{\circ} 53^{\prime} 24^{\prime} \mathrm{E}\right)$. Three popular cultivars, 'Longliangyou Huazhan', 'Longjingyou1212', and 'Jingliangyou1468', were selected to investigate their seed chalkiness ratios in the field each year. The seeds of each variety were harvested from the fields after ripening with a $1 \times 1 \mathrm{~m}$ hollow frame and then 200 seeds of each variety were randomly selected to calculate the chalkiness ratios. All the tests were repeated three times.

\section{Hybrid rice seeds for morphological and physiological analyses}

'Longliangyou Huazhan' seeds were collected from Ava Hainan Breeding Experiment Station during the summer of 2019. The chalky seeds were grouped by a white fluorescent light source. The part of normal endosperm transmitted light whereas the chalky part was opaque (Schaeffer et al. 1986). The chalky seeds were therefore divided into three grades according to the amount of chalky part, and the normal seeds with no chalkiness were used as a control in the test: grade 1, the opaque part was less than one-third of the whole endosperm; grade 2, the opaque part was more than onethird but less than two-thirds of the whole endosperm; grade 3, the opaque part was more than two-thirds of the whole endosperm. For determination of the seeds morphological indexes, the grain length, grain width, and length-width ratio were calculated with 50 seeds of each variety, and the 1000-grain weight was calculated with 1000 seeds of each variety. All the tests were repeated three times. 


\section{Scanning electron microscopic observation of starch granules and aleurone cells}

Scanning electron microscopic (SEM) observation was done according to Nakata et al. (2017) and Feng et al. (2015). Ten grains of normal seeds and from the three grades of chalky seeds in each were chosen. After the seeds were dried under natural conditions, the glumes were removed, the transverse sections of seeds with $2 \mathrm{~mm}$ in thickness each were made, and then the sections were gold-plated. The starch granules of fractured parts and the relative aleurone layer were photographed with a scanning electron microscope (JSM-6360LV, JEOL, Tokyo, Japan) at an accelerating voltage of $20 \sim 28 \mathrm{kV}$ to record the main features of the sections.

\section{Determination of $\alpha$-amylase activity and contents of other relative nutritional ingredients}

The fractured parts of the seeds were collected with a scalpel, using the relative parts of normal seeds with no chalkiness as control. Anthrone colorimetry was used to determine the contents of starch and soluble sugar according to LópezDelgado et al. (2005). The amylose content was determined with iodine colorimetry according to Vilaplana et al. (2012). The amylopectin content was determined with the multi-wavelength method according to Séne et al. (1997). The total sugar content was determined with the 3, 5-dinitrosalicylic acid method according to Lindsay (1973). The soluble protein content was determined with the Bradford method according to Campion et al. (2011). The crude protein content was determined with the Kjeldahl method according to Beljkaš et al. (2010). All the tests were assigned using the kits of Suzhou Comin Biotechnology Co. Ltd. and repeated three times.

\section{Determination of seed germination indexes}

The rice seeds of the four treatments were selected with 200 grains each, washed with 10\% hypochlorous acid for $10 \mathrm{~min}$, and then washed with distilled water three times. The normal seeds were used as a control. After that, the seeds were soaked at $30^{\circ} \mathrm{C}$ for $24 \mathrm{~h}$. Then, the seeds were transplanted on plastic chambers $(17.5 \times 12 \times 5.5 \mathrm{~cm}$, with chamber lids) and cultivated at $30^{\circ} \mathrm{C}$. Germination was estimated to be effective when the length of the radicle equaled to that of the seed, and the length of the germ was over one half of the length of the seed (Luo et al. 2018). The germination potential was determined on the third day after transplantation (d.a.t.). The germination rate, shoot length, root length, and fresh and dry weight of seedlings were investigated and calculated on 7 d.a.t. All the tests were carried out three times.

The germination potential, germination rate, and simplified vigor index were calculated as follows (Eq. 1):

$$
G P=\frac{N_{3 d}}{M} \times 100
$$

where $G P$ is the germination potential, $N_{3 \mathrm{~d}}$ the number of germinated seeds on 3 d.a.t. and $M$ the total number of seeds (Eq. 2):

$$
G R=\frac{N_{7 d}}{M} \times 100
$$

where $G R$ is the germination rate, $N_{7 d}$ the number of germinated seeds on 7 d.a.t. and $M$ the total number of seeds (Eq. 3):

$$
G S=G R \times 100
$$

where GS is the simplified vigor index, and $L$ the length of the shoot.

\section{Determination of germination rate of chalky seeds mimicking peasants' soaking method}

The chalkiness seeds were selected out by a photoselective machine designed by Hunan Ava Seeds Co., Ltd. and 10, 30 and $50 \%$ of the selected chalky seeds were mixed with the normal seeds with no chalkiness. Each treatment was conducted 
with $1.5 \mathrm{~kg}$ of seeds in weight. The seeds were soaked at room temperature (average $26^{\circ} \mathrm{C}$ per day) for $24 \mathrm{~h}$. In the meantime, another set of treatments of 10,30 and $50 \%$ of the selected chalky seeds mixed with healthy seeds were soaked at the same temperature and washed every six hours. After soaking, the germination rate was determined as mentioned above.

\section{Screening microorganisms in seeds}

After the normal seeds with no chalkiness and chalky seeds (grade 3) were washed with sterile water two times, they were transplanted into Petri dishes on two layers of moistened paper which were all pre-sterilized and cultivated at $30^{\circ} \mathrm{C}$. A total of 100 seeds were placed in each Petri dish and all the tests were repeated three times. When apparent bacterial or fungi colonies appeared, the seeds were removed from the Petri dish, and the Petri dish was washed with $10 \mathrm{~mL}$ sterile water. Then the solutions and seeds were used for genome DNA extraction by using the CTAB method separately (Tel-zur et al. 1999). The DNA concentrations and purities were detected using a Nano2000 instrument (Thermo Fisher Scientific, Waltham, MA, USA). Then, eight DNA samples with the amount of DNA greater than $150 \mathrm{ng}$ in each were used for further analyses.

The DNAs were amplified with the specific primers for 16S rRNA V4 and ITS1. The amplified products were purified by gel, and the sequencing libraries were generated by using the Ion Plus Fragment Library Kit 48 rxns (Thermo Fisher Scientific, Waltham, MA, USA). The libraries were then sequenced on an Ion S5TM XL platform (Thermo Fisher Scientific, Waltham, MA, USA). The single-end reads were assigned to the samples according to their barcode sequence and the primer sequence. The high-quality tags were obtained under filtering conditions with the QIIME software (V1.7.0). The reads were compared with the Gold database and the Unite database to remove the chimera sequence using the UCHIME algorithm to acquire the effective reads (Haas et al. 2011). The sequence analysis was performed using the Uparse software (V7.0.1001), and the sequence with 97\% similarity was assigned to the same OTUs (Edgar 2013). All the raw data were uploaded in SRA of NCBI (PRJNA663101, PRJNA663102).

\section{Statistics}

All the tests were carried out at least three times unless otherwise stated, the significant differences were calculated using SPSS13.0 with Duncan's multiple comparison method ( $\mathrm{p}<0.05)$, and the significant differences were labeled with lowercase letters.

\section{RESULTS}

\section{Survey of chalkiness ratios of hybrid rice seeds in Ava Hainan Breeding Experiment Station}

A survey of chalkiness ratios of different hybrid rice varieties was conducted in the Ava Hainan Breeding Experiment Station since 2017 for three years. The chalky grains were found in all of the three cultivars 'Longliangyou Huazhan', 'Longjingyou 1212' and 'Jingliangyou 1468'. The chalkiness ratios ranged from 9.83 to $25.50 \%$ where the annual average temperature was relatively high, from 24.7 to $25.7^{\circ} \mathrm{C}$. These results indicated that the chalkiness phenomenon was common in these hybrid varieties.

\section{Morphological characteristics of hybrid rice seeds with top-gray chalkiness}

The normal seeds and chalky seeds of 'Longliangyou Huazhan' had no significant differences in main properties including grain size, grain length, grain width, and length-width ratio, but the 1000-grain weight became smaller as the chalky grade increased. The 1000-grain weight of grade 3 chalkiness was only $22.0 \mathrm{~g}$, losing $17.1 \%$ in weight as compared to the normal seeds. The color of the normal seeds was golden yellow, whereas the chalky seeds were yellow with a little gray. When the chalky grade of seeds became higher, the seeds were grayer under natural light with the surface color showing a trend of becoming lighter (Fig. 1). 


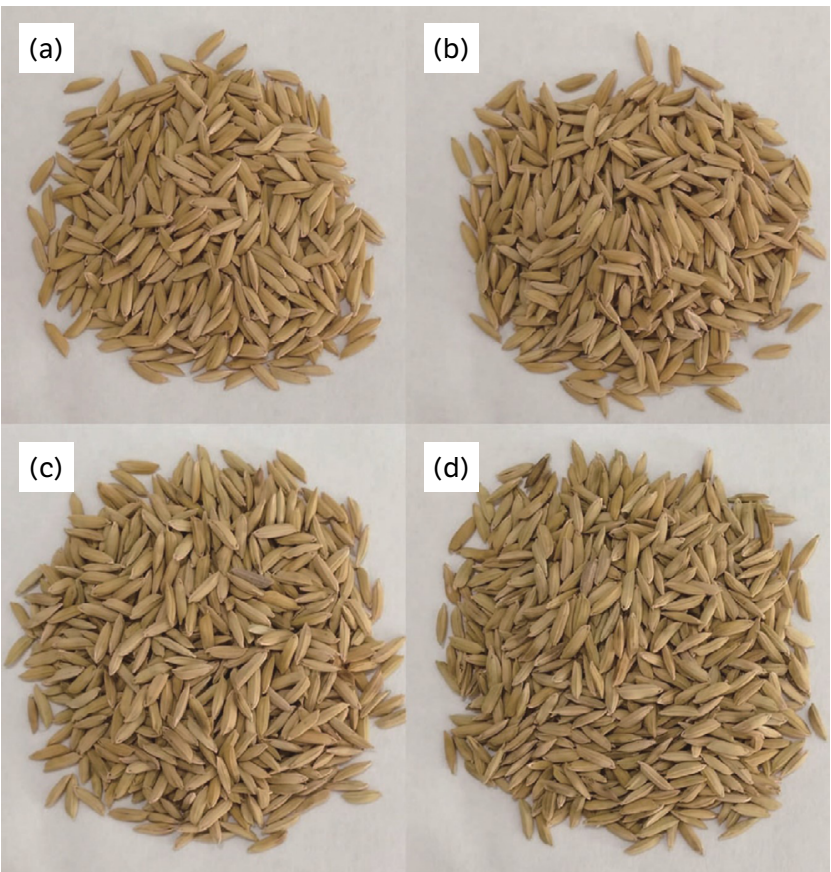

Figure 1. Color of normal seeds with no chalkiness and three grades of chalky seeds under natural light. a) normal seeds with no chalkiness; b) chalky seeds of grade 1 ; c) chalky seeds of grade 2 ; d) chalky seeds of grade 3.

The seeds were irradiated from the back with a white fluorescent light source. The chalky parts were found at the top site of the endosperm opposite to the embryo in the seeds both with glumes and without glumes (Fig. 2). The results showed clearly that the chalkiness originated from the top site of the endosperm.

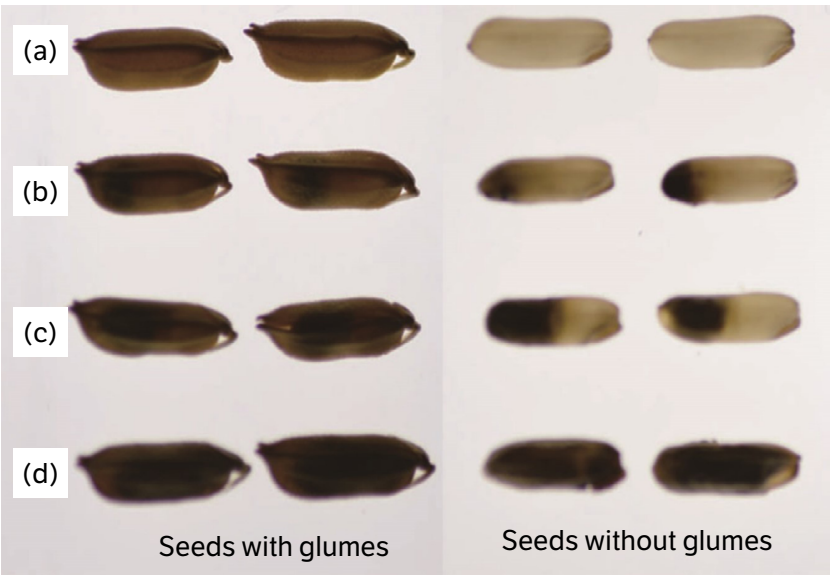

Figure 2. Normal seeds with no chalkiness and three grades of chalky seeds irradiated from back with white fluorescent light source. a) normal seeds with no chalkiness; b) chalky seeds of grade 1 ; c) chalky seeds of grade 2; d) chalky seeds of grade 3.

\section{Scanning electron microscopic observation of endosperm section}

The microscopic images showed that the starch granules of normal seeds were tidy and smooth, whereas those in the chalky seeds were loose, the starch granules were cracked, and there were numerous pits on the surface of the starch granules (Fig. 3). The loose package of starch could result in the observed opaque chalky parts of seeds. On the contrary, the structure of aleurone layer cells both in the normal and chalky seeds remained intact and had no obvious differences (Fig. 4). 


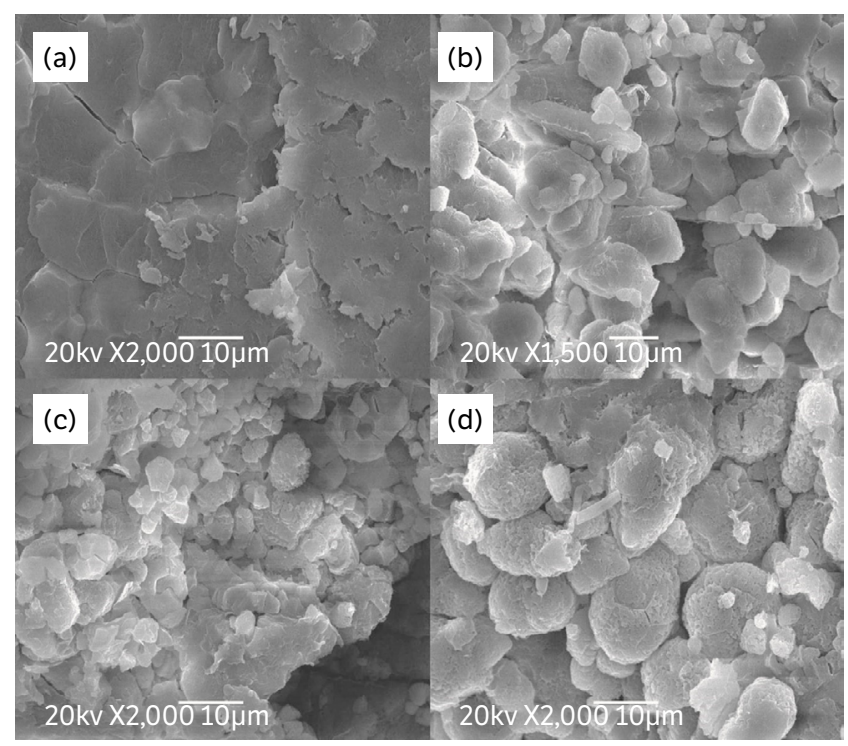

Figure 3. Section of starch granules of normal seeds with no chalkiness and three grades of chalky seeds photographed with scanning electron microscope with JSM-6360LV at $20 \mathrm{kV}$. a) normal seeds with no chalkiness; b) chalky seeds of grade 1; c) chalky seeds of grade 2; d) chalky seeds of grade 3 .

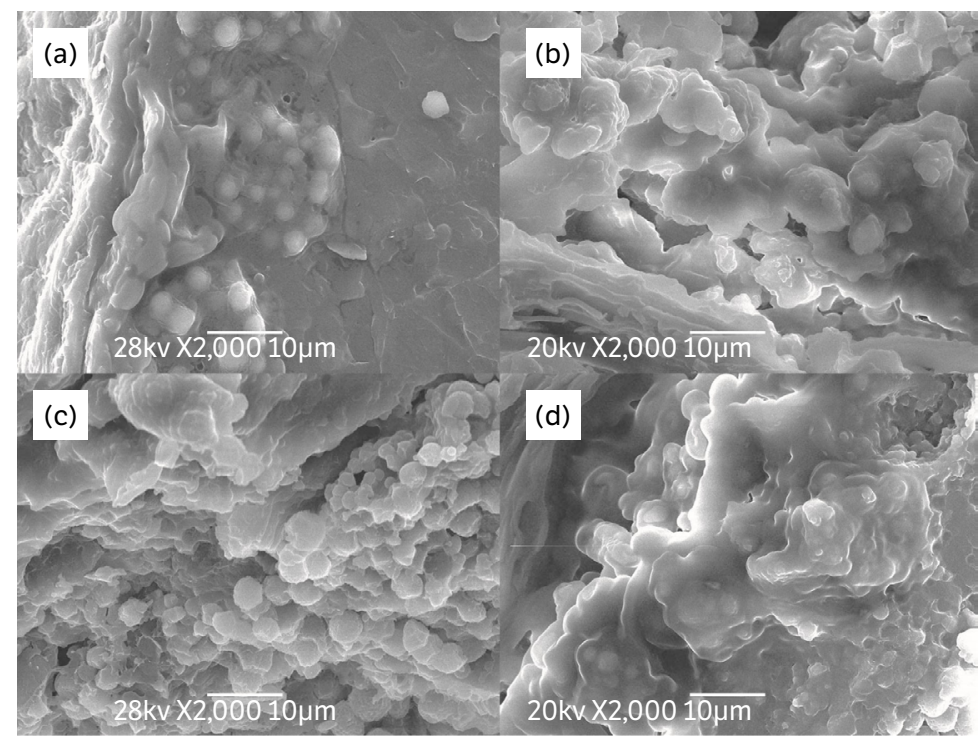

Figure 4. Section of aleurone layer cells of normal seeds with no chalkiness and three grades of chalky seeds photographed with scanning electron microscope with JSM-6360LV at $20 \sim 28 \mathrm{kV}$. a) normal seeds with no chalkiness; b) chalky seeds of grade 1; c) chalky seeds of grade 2 ; d) chalky seeds of grade 3 .

\section{$\alpha$-amylase activity and other nutritional ingredients contents}

Since the activity of starch-lytic $\alpha$-amylase is crucial for grain chalkiness, the $\alpha$-amylase activity and other relative nutritional ingredient contents were determined in this experiment. As shown in Table 1, the $\alpha$-amylase activity of normal seeds was lower than those of the chalky seeds. With the increase of the chalky grade, the $\alpha$-amylase activity increased correspondently, suggesting that $\alpha$-amylase activity was related to the chalky formation. Meanwhile, the contents of soluble sugar, total sugar, soluble protein, and crude protein also increased, whereas the contents of amylose, amylopectin, and starch declined significantly as the chalky grade increased. 
Table 1. $\alpha$-amylase activity and other nutritional ingredients contents of normal seeds with no chalkiness and three grades of chalky seeds.

\begin{tabular}{|c|c|c|c|c|c|c|c|c|}
\hline $\begin{array}{l}\text { Chalky } \\
\text { grade of } \\
\text { seeds }\end{array}$ & $\begin{array}{c}\alpha \text {-amylase } \\
\text { (mg/g) }\end{array}$ & $\begin{array}{c}\text { Amylose } \\
(\mathrm{mg} / \mathrm{g})\end{array}$ & $\begin{array}{c}\text { Amylopectin } \\
(\mathrm{mg} / \mathrm{g})\end{array}$ & $\begin{array}{l}\text { Starch } \\
(\mathrm{mg} / \mathrm{g})\end{array}$ & $\begin{array}{l}\text { Soluble } \\
\text { sugar } \\
\text { (mg/g) }\end{array}$ & $\begin{array}{l}\text { Total sugar } \\
\text { (mg/g) }\end{array}$ & $\begin{array}{l}\text { Soluble } \\
\text { protein } \\
(\mathrm{mg} / \mathrm{g})\end{array}$ & $\begin{array}{c}\text { Crude } \\
\text { protein } \\
(\mathrm{mg} / \mathrm{g})\end{array}$ \\
\hline $\begin{array}{l}\text { Normal } \\
\text { seeds }\end{array}$ & $1.72^{c}$ & $114.36^{a}$ & $349.99^{a}$ & $522.97^{a}$ & $12.28 c$ & $829.96^{b}$ & $15.50^{d}$ & $97.08^{b}$ \\
\hline $\begin{array}{c}\text { Grade } 1 \\
\text { chalkiness }\end{array}$ & $1.97^{\mathrm{b}}$ & $83.89^{b}$ & $363.33^{a}$ & $441.98^{c}$ & $12.34 c$ & $884.71^{a}$ & $17.22^{c}$ & $110.66^{a}$ \\
\hline $\begin{array}{c}\text { Grade } 2 \\
\text { chalkiness }\end{array}$ & $2.11^{b}$ & $93.95^{\mathrm{b}}$ & $382.05^{a}$ & $501.89^{a b}$ & $24.66 \mathrm{~b}$ & $822.99^{b}$ & $32.41^{b}$ & $106.61^{a}$ \\
\hline $\begin{array}{c}\text { Grade } 3 \\
\text { chalkiness }\end{array}$ & $2.52^{\mathrm{a}}$ & $84.32^{b}$ & $288.55^{b}$ & $468.59^{b c}$ & $28.14 a$ & $893.77^{a}$ & $34.47^{a}$ & $104.45^{a b}$ \\
\hline
\end{tabular}

†All tests were repeated three times, and the significant differences were marked by lowercase letters (Duncan method, $p<0.05$ ).

\section{Seeds germination indexes}

The germination indexes of seeds with different chalky grades were investigated to evaluate the influence of chalkiness on seeds germination. As shown in Table 2, germination rate, germination potential, and simplified vigor index of chalky seeds declined significantly when the chalky grade increased. The germination rate, germination potential, and simplified vigor index of grade 3 chalky seeds declined 60.4, 58.0 and 66.7\%, respectively, as compared to those of the normal seeds. The results indicated that the chalkiness seriously influenced the hybrid rice seeds germination.

Table 2. Seeds germination indexes of normal seeds with no chalkiness and three grades of chalky seeds.

\begin{tabular}{cccc}
\hline Chalky grade of seeds & Germination potential (\%) & Germination rate (\%) & Simplified vigor index \\
\hline Normal seeds & $97.25^{\mathrm{a}}$ & $96.50^{\mathrm{a}}$ & $714.58^{\mathrm{a}}$ \\
\hline Grade 1 chalkiness & $78.00^{\mathrm{b}}$ & $75.50^{\mathrm{b}}$ & $513.60^{\mathrm{b}}$ \\
\hline Grade 2 chalkiness & $63.13^{\mathrm{c}}$ & $60.50^{\mathrm{c}}$ & $384.11^{\mathrm{c}}$ \\
\hline Grade 3 chalkiness & $40.88^{\mathrm{d}}$ & $38.25^{\mathrm{d}}$ & $237.83^{\mathrm{d}}$ \\
\hline
\end{tabular}

†All tests were repeated three times, and the significant differences were marked by lowercase letters (Duncan method, $p<0.05$ ).

Besides, the peasants' planting method was mimicked to observe the effects of chalky seeds on healthy seeds during the soaking period. As shown in Table 3, the germination rate of healthy seeds was over 90\%. The germination rate declined significantly when the percentage of chalky seeds increased. The mixed seeds after soaking were infected by microorganisms and had a foul smell. But when the treatment of $50 \%$ of the selected chalky seeds mixed with healthy seeds was washed four times during soaking, the germination rate increased 0.46 fold. This result suggested that the chalky seeds were infected by microorganisms during soaking, and that washing seeds with water during this period inhibited microorganism reproduction.

Table 3. Germination rate with mimicking peasants' soaking method by mixing $10 \%, 30 \%$, and $50 \%$ of selected chalky seeds with normal seeds with no chalkiness.

\begin{tabular}{ccc}
\hline Chalky rate (\%) & \multicolumn{2}{c}{ Germination rate (\%) } \\
\hline & Ordinary soaking & Washed with water per six hours \\
\hline 0 & $90.67^{\mathrm{a}}$ & $91.25^{\mathrm{a}}$ \\
\hline 10 & $86.32^{\mathrm{b}}$ & $87.12^{\mathrm{b}}$ \\
\hline 30 & $78.34 \mathrm{c}$ & $81.28 \mathrm{c}$ \\
\hline 50 & $53.28^{\mathrm{d}}$ & $77.67^{\mathrm{d}}$ \\
\hline
\end{tabular}

†All tests were repeated three times, and the significant differences were marked by lowercase letters (Duncan method, $\mathrm{p}<0.05$ ). 


\section{Seedling morphological indexes}

The seedling morphological indexes reflect the health condition of seedlings. As shown in Table 4, the shoot height, fresh weight per plant, and dry weight per plant of the chalky seeds were lower than those of the normal seeds. The growth status of seedlings of the chalky seeds was worse than that of the normal seeds, indicating the chalkiness could influence seedling quality. Besides, the root length of seedlings of grade 1 chalky seeds became longer than those of normal seeds, but the number of fibrous roots was fewer than that of normal seeds (Fig. 5). It might probably because the chalky seeds were in short of nutrients during germination, and then the seeds responded to this situation through the growth of roots to survive.

Table 4. Seedling morphological indexes of normal seeds with no chalkiness and three grades of chalky seeds.

\begin{tabular}{ccccc}
\hline Chalky grade of seeds & Root length $(\mathbf{c m})$ & Shoot height $(\mathbf{c m})$ & Fresh weight per plant $(\mathbf{g})$ & Dry weight per plant $(\mathbf{g})$ \\
\hline Normal seeds & $6.13^{\mathrm{b}}$ & $7.41^{\mathrm{a}}$ & $1.15^{\mathrm{a}}$ & $0.22^{\mathrm{a}}$ \\
\hline Grade 1 chalkiness & $8.23^{\mathrm{a}}$ & $6.80^{\mathrm{b}}$ & $0.93^{\mathrm{bc}}$ & $0.19^{\mathrm{b}}$ \\
\hline Grade 2 chalkiness & $7.03^{\mathrm{b}}$ & $6.35^{\mathrm{c}}$ & $0.98^{\mathrm{b}}$ & $0.18^{\mathrm{c}}$ \\
\hline Grade 3 chalkiness & $6.66^{\mathrm{b}}$ & $6.20^{\mathrm{c}}$ & $0.850^{\mathrm{c}}$ & $0.15^{\mathrm{d}}$ \\
\hline
\end{tabular}

†All tests were repeated three times, and the significant differences were marked by lowercase letters (Duncan method, $p<0.05$ ).

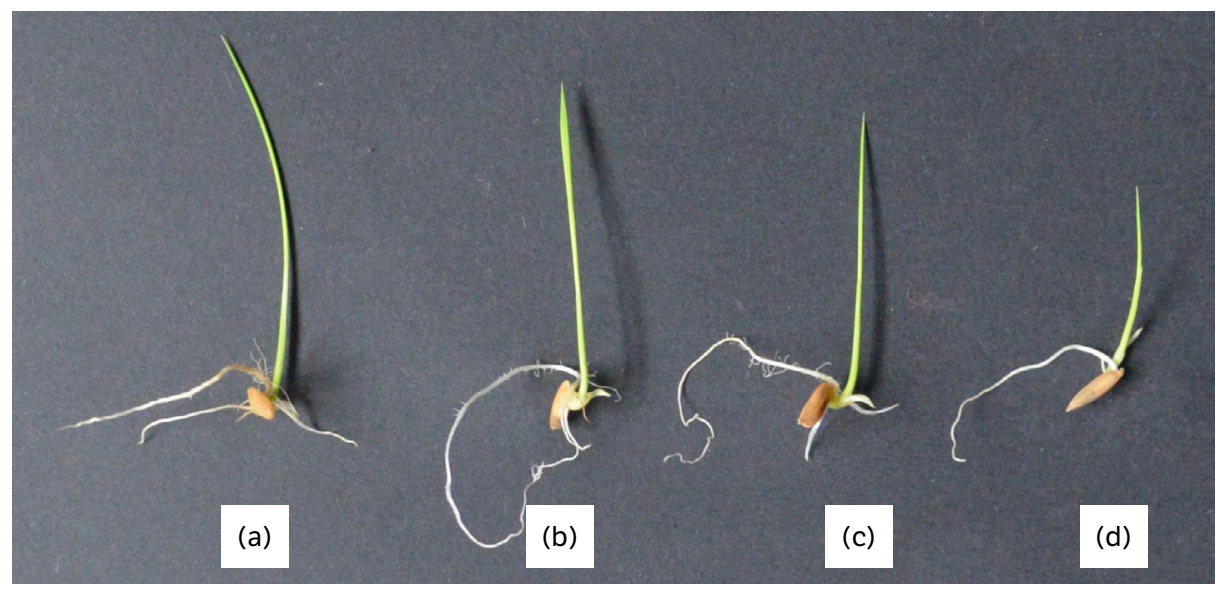

Figure 5. Roots of normal seeds with no chalkiness and three grades of chalky seeds on the seventh day after transplantation (d.a.t.). a) normal seeds with no chalkiness; b) chalky seeds of grade 1; c) chalky seeds of grade 2; d) chalky seeds of grade 3.

\section{Microbial population differences in seeds}

Microbial population differences between normal seeds and chalky seeds were determined by high-throughput amplicon sequencing with $16 \mathrm{~S}$ rRNA and ITS primers. The operational taxonomic units (OTUs) were clustered and showed that microbial populations in chalky seeds changed as compared to the control (Figs. 6a, 6b, 7a and 7b). The relative abundances of Pseudomonas spp. and Fusarium spp. in chalky grade 3 seeds were significantly higher than those of the control (Figs. 6c and 7c), and Pseudomonas mosselii and Fusarium fujikuroi were the dominant populations in the chalky seeds. Since Pseudomonas spp. and Fusarium spp. are ubiquitous and many of them are pathogenic (Shomer et al. 2015; Nucci and Anaissie 2009; Dabboussi et al. 2002), the observed infections could be one of the factors that interfere with seed germination. 

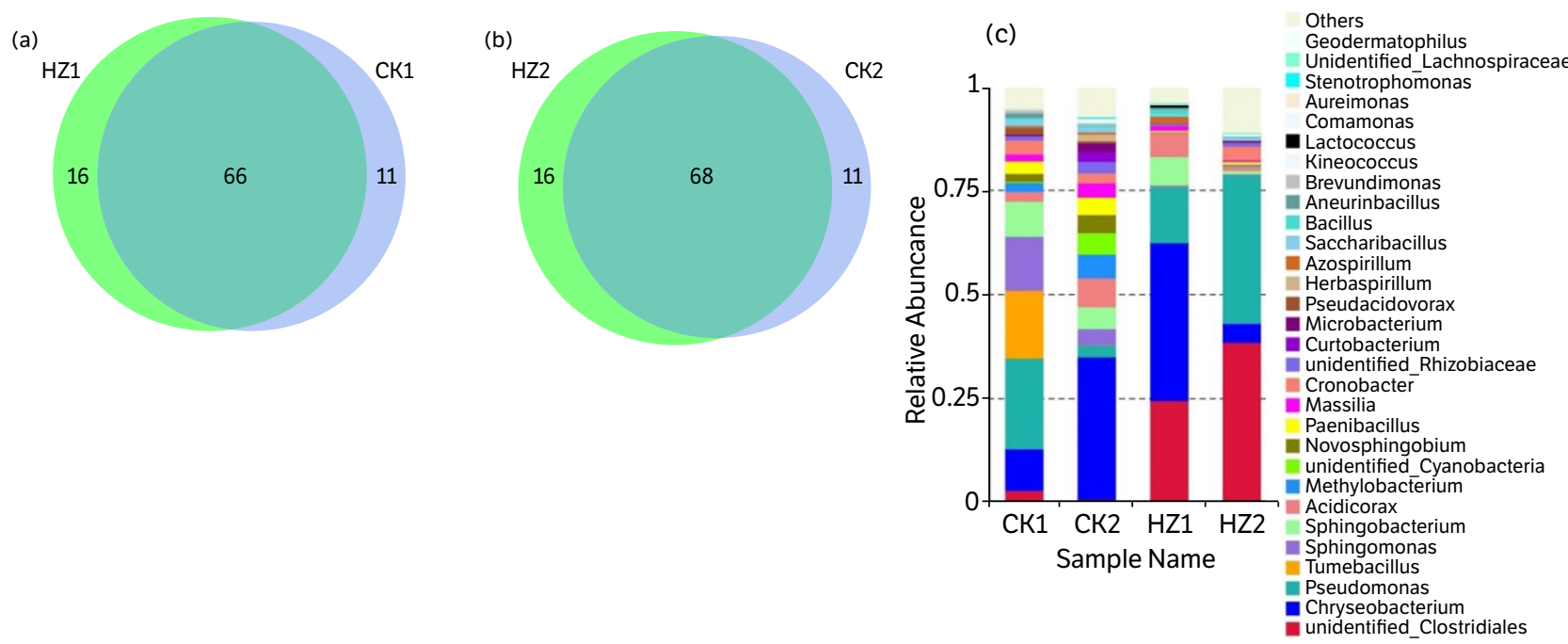

Figure 6. Bacterial population differences in normal seeds with no chalkiness and grade 3 chalky seeds. CK1) bacteria from the solution from normal seeds with no chalkiness; CK2) bacteria from normal seeds with no chalkiness; HZ1) bacteria from the solution of grade 3 chalky seeds; HZ2) bacteria from grade 3 chalky seeds. a) OTU Venn diagram of HZ1 and CK1; b) OTU Venn diagram of HZ2 and CK2; c) relative abundance of bacteria at the genus level.

\section{DISCUSSION}

Rice chalkiness is becoming a widespread problem in rice cultivation areas experiencing the effects of global climate warming. Rice chalkiness is one of the major properties that is controlled by polygenes and influenced by the environmental factors. Under large-scale production, this phenomenon was commonly observed when the average temperature during 20 days after heading exceeded $27^{\circ} \mathrm{C}$. The types of grain chalkiness were usually depicted depending on the chalky site in grains (Yoshioka et al. 2007; Guo et al. 2011; Hayashi et al. 2011). Moreover, the chalkiness in hybrid rice is more serious than that of conventional rice varieties, partly because of the relatively higher grain-filling rate on hybrid rice (Ma et al. 2002) and higher temperatures during heading (Xu et al. 2004).

For hybrid seed production in China, breeders chose to work on subtropical areas due to the long year-round sunny days and warm temperatures. For hybrid rice seeds breeding, breeders' trend to choose sterile lines with the property of the spikelet opening for a relatively long time to receive the pollen more effectively. However, this property also declines the glume closing ability after pollination, resulting in the glume opening phenomenon in hybrid rice seeds. Early studies also revealed that the glume opening phenomenon in hybrid rice seeds lowered the germination rate and germination potential, reducing the seed quality (Li et al. 2015; Yang 2006).

In this experiment, it was found that the location of the chalkiness of hybrid rice seeds was always near the glumes closing site, which was opposite to the embryo. On the contrary, the early reported chalkiness in rice did not show these symptoms (Yoshioka et al. 2007). Meanwhile, the $\alpha$-amylase activity of the chalky part increased as the chalky grade increased, and the surface of starch granules was hydrolyzed to pits. The SEM structure character and the increase of $\alpha$-amylase activity were the typical characteristics of rice chalkiness.

Due to the high temperature during heading, the starch was loosely packaged and the surface of starch granules was decomposed by $\alpha$-amylase. The weight loss of chalky grains was likely due to loose packing of starch granules in chalky grains (Ashida et al. 2009; Kaneko et al. 2016). As a result, the amylose and starch content would decline in the chalky part. Owing to the high humidity in Hainan Province and to the longer spikelet opening time of the two-line sterile variety of rice, the endosperms likely became more susceptible to bacteria and fungi during development.

Early studies showed that the chalky kernel of rice was more rigid and of higher hardness in texture, owing to less amylose, more chain amylopectin, and less protein (Cheng et al. 2005; Chun et al. 2009). But in this experiment, it was found that the amylopectin content of the chalky part declined, whereas the protein content of this part increased. Besides, the contents of 
(a)

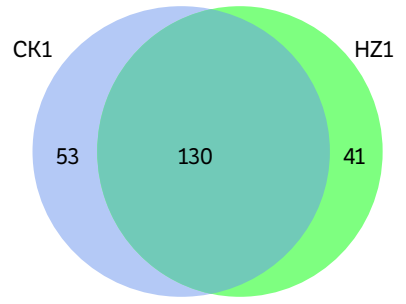

(b)

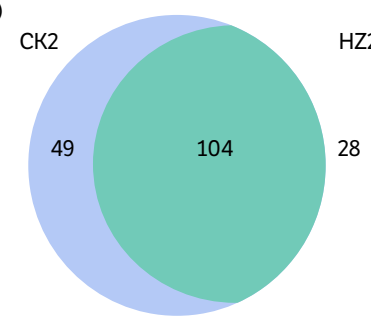

HZ2

\section{(c)}

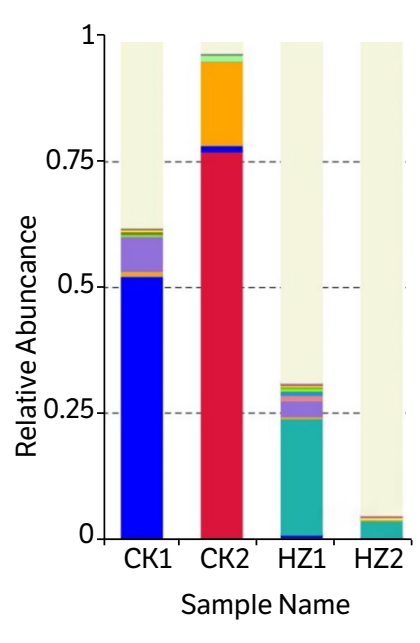

Others

Metarhizioum

Beauveria

Cyrenella

unidentified_Mortierellomycota

Ceratobasidium

- Cladosporium

Aspergillus

Symmetrps'pra

- Geomyces

Brachyphoris

- Wallemia

Kurtzmanomyces

Saitozyma

Mortierella

Alternaria

Rhizopus

Coprinellus

Diutina

Dactylonectria

Hannaella

Sarocladium

Rhodotorula

Kwoniella

Penicillium

Moesziomyces

Cryptococcus

Rhodosporidiobolus

Fusarium

Papiliotrema

Papiliotremalaris

CK1 - fungi from the solution from normal seeds with no chalkiness; CK2 - fungi from healthy seeds; HZ1 - fungi from the solution of grade 3 chalky seeds; HZ2 fungi from grade 3 chalky seeds. A - OTU Venn diagram of HZ1 and CK1; B - OTU Venn diagram of HZ2 and CK2; C- relative abundance of fungi at the genus level. Figure 7. Fungal population differences in normal seeds with no chalkiness and grade 3 chalky seeds.

soluble sugar and total sugar in the chalky seeds also became higher than those of the control. Increased sugar levels likely caused the metabolism level in this kind of chalky grains to be higher than normal. The seeds could also be more susceptible to pathogenic microorganisms because the spikelet opening time of the two-line sterile variety was relatively long and the glumes did not close or did not close tightly. The pathogenic microorganisms could infect the endosperm easily, leading to a higher metabolism level after heading in plants or during the storage of seeds at high temperatures with high humidity. On the other hand, the seeds after harvest would be dried by relatively high temperatures during seeds processing. During the process, the abundant nutrients in the chalky parts including soluble sugars and proteins could lead to a Maillard reaction to darken the color of these parts in the endosperm (Kerler et al. 2010).

\section{CONCLUSION}

A new type of chalkiness in hybrid rice seeds was observed in this work. The chalky parts were gray-colored and originated from the top of the endosperm. The starch granules of the fractured parts were typical of a chalky rice structure and were susceptible to dominant pathogenic microorganisms, such as P. mosselii and F. fujikuroi.

The chalkiness in the hybrid rice seeds resulted in a lower germination rate, lower germination potential, and lower seed vigor correspondently during germination. To avoid losses caused by top-gray chalkiness in hybrid rice breeding, the following measures can be considered: First, seeds should be dried in time after harvest to reduce amylase activity; second, the seeds should be screened with white fluorescent light before packing to avoid cross infection during germination; and lastly, the site of the breeding station should be selected according to the historical weather data including the annual average temperature, humidity, and rainfall.

\section{AUTHORS' CONTRIBUTION}

Conceptualization, Hu Y., Chen Y. and Tang J.; Methodology, Yuan H. and Zhang H.; Investigation, Jin C. and Tang J.; Writing and Editing Manuscript, Hu Y.; Funding Acquisition, Liu A.; Supervision, Hu Y. 


\section{DATA AVAILABILITY STATEMENT}

Data will be avaliable upon request.

\section{FUNDING}

Scientific Research Project of Public Welfare Industry (Agriculture)

Grant No. 201503123- 05

National Natural Science Foundation of China

[http://doi.org/10.13039/501100001809]

Grant No: 31071353

\section{ACKNOWLEDGMENTS}

We should like to thank all the staff of the Quality Inspection Department of Hunan Ava Seeds Co., Ltd. for their assistance in this work.

\section{REFERENCES}

Ashida, K., lida, S. and Yasui, T. (2009). Morphological, Physical, and Chemical Properties of Grain and Flour from Chalky Rice Mutants. Cereal Chemistry, 86, 225-231. https://doi.org/10.1094/CCHEM-86-2-0225

Beljkaš, B., Matić, J., Milovanović, I., Jovanov, P., Mišan, A. and Šarić, L. (2010). Rapid method for determination of protein content in cereals and oilseeds: validation, measurement uncertainty and comparison with the Kjeldahl method. Accreditation and Quality Assurance, 15, 555-561. https://doi.org/10.1007/s00769-010-0677-6

Bridgemohan, P. and Bridgemohan, R. S. H. (2014). Crop nutrition studies on grain filling and chalkiness in rice. Journal of Plant Breeding and Crop Science, 6, 144-152. https://doi.org/10.5897/JPBCS2014.0474

Campion, E. M., Loughran, S. T. and Walls, D. (2011). Protein Quantitation and Analysis of Purity. In D, Walls, and S. Loughran (Eds.), Protein Chromatography: Methods in Molecular Biology (Methods and Protocols) (p. 229-258). Totowa: Humana Press. https://doi. org/10.1007/978-1-60761-913-0_13

Cheng F. M., Zhong, L. J., Wang, F. and Zhang, G. P. (2005). Differences in cooking and eating properties between chalky and translucent parts in rice grains. Food Chemistry, 90, 39-46. https://doi.org/10.1016/j.foodchem.2004.03.018

Chun, A., Song, J., Kim, K.-J. and Lee, H.-J. (2009). Quality of head and chalky rice and deterioration of eating quality by chalky rice. Journal of Crop Science and Biotechnology, 12, 239-244. https://doi.org/10.1007/s12892-009-0142-4

Dabboussi, F., Hamze, M., Singer, E., Geoffroy, V., Meyer, J.-M. and Izard, D. (2002). Pseudomonas mosselii sp. Nov., a novel species isolated from clinical specimens. International Journal of Systematic and Evolutionary Microbiology, 52, 363-376. https://doi. org/10.1099/00207713-52-2-363

Edgar, R. C. (2013). UPARSE: highly accurate OTU sequences from microbial amplicon reads. Nature Methods, 10, 996-998. https:// doi.org/10.1038/nmeth.2604 
Feng, F., Li, J., Guo, D., Wang, H., Qian, Y. and Mo, Y. (2015). Effect of different air temperature in different cropping years on development of seed endosperm and germination characteristics in 'over-expression OsPIN1a' and wild type rice. Journal of Nuclear Agricultural Sciences, 29, 2198-2207. https://doi.org/10.11869/j.issn.100-8551.2015.11.2198

Fu, C., Wang, F., Liu, W., Liu, D., Li, J., Zhu, M., Liao, Y., Liu, Z., Huang, H., Zeng, X. and Ma, X. (2017). Transcriptomic analysis reveals new insights into high-temperature-dependent glume-unclosing in an elite rice male sterile line. Frontiers in Plant Science, 8, 112. https:// doi.org/10.3389/fpls.2017.00112

Guo, T., Liu, X., Wan, X., Weng, J., Liu, S., Liu, X., Chen, M., Li, J., Su, N., Wu, F., Cheng, Z., Guo, X., Lei, C., Wang, J., Jiang, L. and Wan, J. (2011). Identification of a stable quantitative trait locus for percentage grains with white chalkiness in rice (Oryza sativa). Journal of Integrative Plant Biology, 53, 598-607. https://doi.org/10.1111/j.1744-7909.2011.01041.x

Haas, B. J., Gevers, D., Earl, A. M., Feldgarden, M., Ward, D. V., Giannoukos, G., Ciulla, D., Tabbaa, D., Highlander, S. K., Sodergren, E., Methé, B., DeSantis, T. Z., Petrosino, J. F., Knight, R. and Birren, B. W. (2011). Chimeric 16S rRNA sequence formation and detection in Sanger and 454-pyrosequenced PCR amplicons. Genome Research, 21, 494-504. https://doi.org/10.1101/gr.112730.110

Hartweck, L. M. and OIszewski, N. E. (2006). Rice GIBBERELLIN INSENSITIVE DWARF1 Is a gibberellin receptor that illuminates and raises questions about GA signaling? The Plant Cell, 18, 278-282. https://doi.org/10.1105/tpc.105.039958

Hayashi, M., Sugiura, K., Kuno, C., Endo, I., Tanaka, Y. and Yamauchi, A. (2011). Reduction of rice chalky grain by deep and permanent irrigation method; effect on growth and grain quality of rice. Plant Production Science, 14, 282-290. https://doi.org/10.1626/pps.14.282

Ishimaru, T., Horigane, A. K., Ida, M., Iwasawa, N., San-oh, Y. A., Nakazono, M., Nishizawa, N. K., Masumura, T., Kondo, M. and Yoshida, M. (2009). Formation of grain chalkiness and changes in water distribution in developing rice caryopses grown under high-temperature stress. Journal of Cereal Science, 50, 166-174. https://doi.org/10.1016/j.jcs.2009.04.011

Kaneko, K., Sasaki, M., Kuribayashi, N., Suzuki, H., Sasuga, Y., Shiraya, T., Inomata, T., Itoh, K., Baslam, M, and Mitsui, T. (2016). Proteomic and glycomic characterization of rice chalky grains produced under moderate and high-temperature conditions in field system. Rice, 9, 26. https://doi.org/10.1186/s12284-016-0100-y

Kerler, J., Winkel, C., Davidek, T. and Blank, I. (2010). Basic chemistry and process conditions for reaction flavours with particular focus on Maillard-type reactions. In J. Andrew, and S. T. Robert (Eds.), Food flavour technology (p. 51-88). Hoboken: John Wiley \& Sons. https://doi.org/10.1002/9781444317770.ch3

Li, Y.-N, Sun, J., Ding, Q.-S, Liu, Y. -Y. and Ding, W.-M. (2015). Effects of glume-gapping and kernel-cracking of hybrid rice seed on seed germination and seedling growth. Hybrid Rice, 30, 71-74. https://doi.org/10.16267/j.cnki.1005-3956.201504024

Lindsay, H. (1973). A colorimetric estimation of reducing sugars in potatoes with 3,5-dinitrosalicylic acid. Potato Research, 16, 176-179. https://doi.org/10.1007/BF02356048

López-Delgado, H., Zavaleta-Mancera, H. A., Mora-Herrera, M. E., Vázquez-Rivera, M., Flores-Gutiérrez, F. X. and Scott, I. M. (2005). Hydrogen peroxide increases potato tuber and stem starch content, stem diameter, and stem lignin content. American Journal of Potato Research, 82, 279-285. https://doi.org/10.1007/BF02871957

Lovegrove, A., Barratt, D. H. P., Beale, M. H. and Hooley, R. (1998). Gibberellin-photoaffinity labelling of two polypeptides in plant plasma membranes. The Plant Journal, 15, 311-320. https://doi.org/10.1046/j.1365-313X.1998.00209.x

Luo, B., Pan, D.-Y., Gao, Q., Chen, Q., Hou, P.-C., Song., P. and Wang, C. (2018). Design and experiment of rice program control germination system in cold region based on internet of things. Transactions of the Chinese Society of Agricultural Engineering, 34, $181-185$.

Ma, J., Zhou, K.-D., Ma, W.-B., Wang, X.-D., Ming, D.-F. and Yan, Z.-B. (2002). Study on the relationship of the characteristics of vascular bundles in the first internode and grain-filling of heavy panicle type hybrid rice. Agricultural Sciences in China, 1, 631-635. 
Nakata, M., Fukamatsu, Y., Miyashita, T., Hakata, M., Kimura, R., Nakata, Y., Kuroda, M., Yamaguchi, T. and Yamakawa, H. (2017). High temperature-induced expression of rice $\alpha$-amylases in developing endosperm produces chalky grains. Frontiers in Plant Science, 8 , 2089. https://doi.org/10.3389/fpls.2017.02089

Nucci, M. and Anaissie, E. J. (2009). CHAPTER 13 - Hyalohyphomycosis. In E. J. Anaissie, M. R. McGinnis, and M. A. Pfaller (Eds.), Clinical mycology (SECOND EDITION) (p. 309-327). London: Churchill Livingstone. https://doi.org/10.1016/B978-1-4160-5680-5.00013-X Schaeffer, G. W., Sharpe Junior, F. T., Carnahan, H. L. and Johnson, C. W. (1986). Anther and tissue culture-induced grain chalkiness and associated variants in rice. Plant Cell, Tissue and Organ Culture, 6, 149-157. https://doi.org/10.1007/BF00180798

Séne, M., Thévenot, C. and Prioul, J. L. (1997). Simultaneous spectrophotometric determination of amylose and amylopectin in starch from maize kernel by multi-wavelength analysis. Journal of Cereal Science, 26, 211-221. https://doi.org/10.1006/jcrs.1997.0124

Shomer, N. H., Holcombe, H. and Harkness, J. E. (2015). Chapter 6 - Biology and Diseases of Guinea Pigs. In J. G. Fox, L. C. Anderson, G. M. Otto, K. R. Pritchett-Corning, and M. T. Whary (Eds.), Laboratory Animal Medicine (Third Edition) (p. 247-283). Cambridge: Academic Press. https://doi.org/10.1016/B978-0-12-409527-4.00006-7

Tel-zur, N., Abbo, S., Myslabodski, D. and Mizrahi, Y. (1999). Modified CTAB Procedure for DNA Isolation from Epiphytic cacti of the Genera Hylocereus and Selenicereus (Cactaceae). Plant Molecular Biology Reporter, 17, 249-254. https://doi.org/10.1023/A:1007656315275

Ueguchi-Tanaka, M., Nakajima, M., Katoh, E., Ohmiya, H., Asano, K., Saji, S., Hongyu, X., Ashikari, M., Kitano, H., Yamaguchi, I. and Matsuoka M. (2007). Molecular interactions of a soluble gibberellin receptor, GID1, with a rice DELLA protein, SLR1, and gibberellin. The Plant Cell, 19, 2140-2155. https://doi.org/10.1105/tpc.106.043729

Vilaplana, F., Hasjim, J. and Gilbert, R. G. (2012). Amylose content in starches: toward optimal definition and validating experimental methods. Carbohydrate Polymers, 88, 103-111. https://doi.org/10.1016/j.carbpol.2011.11.072

Walker, R. P., Waterworth, W. M., Beale, M. H. and Hooley, R. (1994). Gibberellin-photoaffinity labeling of wild oat (Avena fatua L.) aleurone protoplasts. Plant Growth Regulation, 15, 271-279. https://doi.org/10.1007/BF00029900

Wang, X.-N. and Meng, W.-D. (2005). Progress in research on utilization of two-line hybrid rice heterosis. Chinese Agricultural Science Bulletin, 21, 140-143.

Xu, F.-X., Zheng, J.-K., Zhu, Y.-C., Wang, G.-X., Yang, D.-J. and Liu, K. (2004). Effect of super sparse cultivation on head milled rice percentage and chalkiness in hybrid rice varieties in the eastern and southern districts of Sichuan Province. Acta Phytoecologica Sinica, 28, 686-691. https://doi.org/10.17521/cjpe.2004.0092

Yang, J.-J (2006). Glume dehiscence of hybrid rice seeds and its harmfulness. Hybrid Rice, 21, 57-60. https://doi.org/10.16267/j. cnki.1005-3956.2006.01.026

Yano, K., Aya, K., Hirano, K., Ordonio, R. L., Ueguchi-Tanaka, M. and Matsuoka, M. (2015). Comprehensive gene expression analysis of rice aleurone cells: probing the existence of an alternative gibberellin receptor. Plant Physiology, 167, 531-544. https://doi.org/10.1104/ pp.114.247940

Yoshioka, Y., Iwata, H., Tabata, M., Ninomiya, S. and Ohsawa, R. (2007). Chalkiness in rice: potential for evaluation with image analysis. Crop Science, 47, 2113-2120. https://doi.org/10.2135/cropsci2006.10.0631sc 